\title{
PENGARUH BOTTOM ASH SEBAGAI PENGGANTI PASIR DAN LIMBAH KARBIT SEBAGAI BAHAN TAMBAH SEMEN TERHADAP BERAT JENIS, KUAT TEKAN, DAN ABSORBSI BATAKO
}

\author{
Nur Ali', Rofikatul Karimah² , H. E.Meiyanto ${ }^{3}$ \\ 1,2,3 Jurusan Teknik Sipil Fakultas Teknik - Universitas Muhammadiyah Malang \\ Alamat korespondensi : Jalan Raya Tlogomas 246 Malang 65144
}

\begin{abstract}
Basically concrete brick is formed from cement, sand and water, than a breakthrough made in manufacturing of concrete brick with the utilization of wastes which have no economic value are also widely available in the environment than is waste of bottom ash an carbide. In this research, a normal concrete brick consist of cement, sand, and water which given variation of carbide waste ranging from $10 \%, 20 \%$, and $30 \%$, afterwards a replacement of sand by bottom ash is made with a given variation of carbide waste $10 \%, 20 \%$, and $30 \%$. Result of the research that applying sand as subtle aggregate and waste of carbide as additional material for cement gets the best result on the variation of carbide waste 30\% with strength of compression 69,10 MPa and 3,58\% absorption capacity, it is better rather than normal concrete brick on the variation of carbide waste $0 \%$ with compressive strength of 48,74 MPa and 5,49 absorption capacity. After wards, by doing replacement of sand with bottom ash as subtle aggregate and added waste carbideas its variations is obtained the best results in the variation of carbide waste 30\% with compressive strength 52,37 MPa and 6,92 of absorption capacity better rather than 0\% of variation carbide waste with strength of compession 19,64 MPa and 12,01 of absorption capacity.
\end{abstract}

Keyword: Concrete Brick, bottom ash, waste carbide.

\begin{abstract}
Abstrak
Pada dasarnya batako terbentuk dari semen, pasir dan air, dari terobosan yang dibuat dalam pembuatan batako dengan pemanfaatan limbah yang tidak memiliki nilai ekonomis juga banyak tersedia di lingkungan daripada buang-buang bottom ash sebuah karbida. Dalam penelitian ini, batu batako normal terdiri dari semen, pasir, dan air yang diberikan variasi limbah karbida berkisar antara 10\%,20\%, dan $30 \%$, kemudian pengganti pasir oleh bottom ash dibuat dengan variasi tertentu karbida buang $10 \%, 20 \%$, dan $30 \%$. Hasil penelitian yang menerapkan pasir sebagai agregat halus dan limbah karbit sebagai bahan tambahan untuk semen mendapat hasil terbaik pada variasi limbah karbida $30 \%$ dengan kekuatan kompresi 69,10 MPa dan kapasitas penyerapan 3,58\%, lebih baik daripada bata beton normal pada variasi limbah karbida $0 \%$ dengan kuat tekan $48,74 \mathrm{MPa}$ dan kapasitas penyerapan 5,49. Setelah bangsal, dengan melakukan penggantian pasir dengan bottom ash sebagai agregat halus dan limbah ditambahkan carbideas variasinya diperoleh hasil terbaik pada variasi limbah karbida $30 \%$ dengan kuat tekan 52,37 MPa dan 6,92 dari kapasitas penyerapan yang lebih baik daripada $0 \%$ variasi limbah karbida dengan kekuatan compession 19,64 MPa dan 12,01 kapasitas penyerapan.
\end{abstract}

Kata Kunci: Batako, abu batu, limbah karbit.

\section{PENDAHULUAN}

Seiring pesatnya perkembangan dalam bidang hal konstruksi, penelitian untuk mendapatkan bahan bangunan yang lebih kuat dan baik terus dilakukan. Serta Mengingat perkembangan saat ini, harga material cenderung mengalami kenaikan, maka dari itu dilakukan terobosan dalam pembuatan batako dengan pemanfaatan limbah-limbah yang tidak memiliki nilai ekonomis juga banyak tersedia di lingkungan, dalam hal ini adalah bottom ash dan limbah karbit.

Bottom ash adalah limbah pembakaran batu bara, sedangkan limbah karbit adalah limbah padat yang berasal dari proses pembuatan gas asetilen atau sisa-sisa dari proses pengelasan dengan las karbit, namun hingga saat ini limbah karbit belum di manfaatkan secara optimal. 
Pada penelitian ini bottom ash akan di aplikasikan sebagai pengganti pasir, dan limbah karbit sebagai bahan tambah semen pada pembuatan bendauji batako. Diharapkan nantinya batako dengan bahan tambah berupa limbah karbit dan abu dasar bottom ash sabagai pengganti pasir dapat digunakan di kalangan umum serta tidak mengganggu lingkungan hidup disekitarnya·

\section{Batako}

Batako merupakan bahan bangunan yang berupa bata cetak alternatif pengganti batu bata yang tersusun dari komposisi antara pasir, semen (Portland)dan air dengan perbandingan 1 semen : 4 pasir. Batako difokuskan sebagai konstruksikonstruksi dinding bangunan nonstruktural. Supribadi (1986: 5) mengatakan bahwa batako adalah " semacam batu cetak yang terbuat dari campuran tras, kapur, dan air atau dapat dibuat dengan campuran semen, kapur, pasir dan ditambah air yang dalam keadaan rekat (pollen) dicetak menjadi balokbalok dengan ukuran tertentu". Batako yang baik adalah yang masing-masing permukaanya rata dan saling tegak lurus serta mempunyai kuat tekan yang tinggi. Persyaratan batako menurut PUBI 1982 pasal 6 antara lain adalah " permukaan batako harus mulus, berumur minimal satu bulan, pada waktu pemasangan harus sudah kering, berukuran panjang $400 \mathrm{~mm}$, lebar $200 \mathrm{~mm}$ dan tebal 100-200 mm, kadar air 25-35\% dari berat, dengan kuat tekan antara 2$7 \mathrm{~N} / \mathrm{mm} 2 "$.

\section{Bahan - Bahan Penyusun Batako}

Bahan-bahan penyusun beton ringan nonringan diklasifikasikan sebagai berikut:

- Semen

Semen adalah suatu bahan yang mempunyai sifat adhesi dan kohesi yang memungkinkan melekatnya bahan-bahan menjadi suatu masa yang padat dan mengisi rongga-rongga diantara butiranbutiran agregat. Walaupun semen hanya mengisi lebih kurang $10 \%$ dari volume mortar (Tjokrodimulyo, 1992).

Semen dibuat dengan melalui beberapa langkah, sehingga sangat halus dan memiliki sifat adhesif maupun kohesif.Semen diperoleh dengan membakar secara bersamaan, suatu campuran dari calcareous (yang mengandung kalsium karbonat atau batu gamping) dan argillaceous (yang mengandung alumina) dengan perbandingan tertentu. Secara mudahnya, kandungan semen portland ialah: kapur, silika dan alumina.

\section{- Pasir}

Pasir adalah bahan bangunan yang banyak dipergunakan dari struktur paling bawah hingga paling atas dalam bangunan.Baik sebagai pasir urug, adukan hingga campuran batako. Menurut standar nasional indonesia (SK SNI - S - $04-1989-\mathrm{F}$ : 28) disebutkan mengenai persyaratan pasir atau agregat halus yang baik.

- Air

Air merupakan bahan dasar pembuat beton yang penting karena diperlukan untuk bereaksi dengan semen serta sebagai bahan pelumas antara butir- butir agregat agar mudah dikerjakan dan mudah dipadatkan. Air diperlukan untuk bereaksi dengan semen, serta untuk menjadi bahan pelumas antar butiran agregat, agar dapat dengan mudah dikerjakan dan dipadatkan, air yang diperlukan sekitar 30\% dari berat semen. FAS tidak kurang dari 0,35 . kelebihan air ini yang dipakai sebagai pelumas. Air yang memenuhi persyaratan air minum memenuhi syarat pula untuk campuran beton, tetapi tidak berarti air campuran beton harus memenuhi syarat-syarat air minum.

\section{- Bottom ash}

Bottom ash adalah bahan buangan dari proses pmbakaran batu bara pada pembangkit tenaga yang mempunyai ukuran partikel lebih besar dan lebih berat dari pada (fly ash). Oleh sebab itu bottom ash akan jatuh pada dasar tungku pembakaran (boiler) dan terkumpul pada penampung debu (ash hopper) lalu dikeluarkan dari tungku dengan cara di semprot dengan air untuk kemudian dibuang atau dipakai untuk keperluan tertentu (Coal Bottom Ash / Boiler Slag-Material Description, 2000)

\section{- $\quad$ Limbah Karbit}

Limbah karbid adalah sisa dari reaksi karbid terhadap air yangmenghasilkan gas asetilin. di golongkan dalam jenis kapur padam.

Menurut Kirk dan Othmer yang dikutip P. Sumardi (1991 : 38)menyatakan bahwa karbit yang 
diperdagangkan bukan senyawa murni tetapi merupakan campuran yang terdiri dari $\mathrm{CaC} 2$ kelebihan $\mathrm{CaO}$ dan sedikit zat pengotor. Kalsium karbit yang merupakan hasil sampingan pembuatan gas acetelin adalah berupa padatan berwarna putih kehitaman atau keabu-abuan dengan berat jenis sebesar 2.22. Awal dihasilkannya limbah karbit berupa koloid (semi cair) karena gas ini mengandung gas dan air. Setelah 3-7 hari,gas yang terkandung menguap perlahan seiring dengan penguapan gas dan airkapur limbah karbit mulai mengering, berubah menjadi gumpalan-gumpalan yang rapuh dan mudah di hancurkan serta dapat menjadi serbuk.

\section{Berat Jenis Batako}

Mengacu pada SK SNI 03-1969-1990 tentang pengujian berat jenis. Prosedur pengujian meliputi tahapan sebagai berikut: keringkan dalam oven, kemudian dinginkan. Timbang dengan ketelitian 0,5 gr (Bk), timbang benda uji dalam air (Ba). Kemudian hitung dengan rumus:

$$
\mathrm{Bj}=\frac{B k}{(B k-B a)}
$$

Dimana :

$B j=$ Berat jenis

$\mathrm{Bk}=$ Berat benda uji kering oven

$\mathrm{Ba}=$ Berat benda uji dalam air Kuat Tekan

Mengacu pada pada SK SNI M-14-1989-F tentang pengujian kuat tekan beton. Yang dimaksud kuat tekan beton adalah besarnya beban persatuan luas yang menyebabkan benda uji beton hancur bila dibebani dengan gaya tekan tertentu dihasilkan oleh mesin tekan. (Dinas Pekerjaan Umum, 1989: 4).

$$
f^{\prime} \mathrm{c}=\frac{P}{A}
$$

Dimana :

$f^{\prime} \mathrm{c}=$ kuat tekan beton $\left(\mathrm{kg} / \mathrm{cm}^{2}\right)$

$P^{\prime} \quad=$ beban maksimum yang mengakibatkan silinder hancur $(\mathrm{kg})$

A = luas penampang tertekan benda uji $\left(\mathrm{cm}^{2}\right)$

\section{Absorbsi \\ Absorbsi dihitung dengan berdasarkan SNI 03- 6433-2000 sebagaimana terlihat dalam rumus dibawah ini :}

$\%$ absorbsi $\left.=\frac{B-A}{A}\right) \times 100 \%$

Dimana :

$\mathrm{B}=$ Berat sampel basah

$\mathrm{A}=$ Berat sampel kering

\section{METODE PENELITIAN}

\section{Rancangan Penelitian}

Pelaksanaan prapenelitian yang meliputi pemeriksaan serta pengujian bahan, perawatan dan pengujian batako dilakukan di Laboratorium Teknologi Beton Fakultas Teknik Jurusan Sipil Universitas Muhammadiyah Malang.J.L. Raya Tlogomas km. 8 Malang. Untuk pembuatan batakonya sendiri dilakukan di home industri yang ada di Desa Bocek Karang ploso - Malang.

\section{HASIL DAN PEMBAHASAN}

\section{Hasil Pemeriksaan Bahan}

\section{Semen}

Pemeriksaan semen meliputi: pemeriksaan berat jenis. Dari hasil pengujian berat jenis semen di atas berat jenis semen rata -rata $3.15 \mathrm{gram} / \mathrm{cm}^{3}$ berarti telah memenuhi syarat berat jenis semen yaitu sekitar 3,15 - $3.17 \mathrm{gram} / \mathrm{cm}^{3}$, dapat ditarik kesimpulan bahwa semen Portland type I produksi PT. Semen Gresik dinyatakan layak digunakan sebagai bahan pengikat campuran batako.

\section{Pasir}

Dari semua hasil pemeriksaan material agregat halus meliputi lolos saringan No. 200, analisa saringan, berat jenis, dan absorbsi dapat dikatakan bahwa pasir alam ini memenuhi syarat sebagai bahan campuran batako.

\section{Bottom ash}

Dalam penelitian ini dilakukan beberapa uji pemeriksaan yaitu pemeriksaan gradasi agregat, berat jenis, dan penyerapan agregat. 


\section{Limbah karbit}

Dalam penelitian ini semen dilakukan beberapa uji pemeriksaan antara lain kehalusan, berat jenis, dan setting time.

Dari semua hasil limbah karbit diharapkan dalam pencampurannya dapat bersifat homogen dan dapat meningkatkan mutu batako.

\section{Perencanaan Campuran Batako}

Setelah hasil pengujian bahan telah diketahui, selanjutnya dilakukan perencanaan campuran batako, dari hasil campuran batako didapat volume campuran 1 benda uji kubus.

Tabel 1. Properti Benda Uji

\begin{tabular}{|c|c|c|c|c|c|c|}
\hline \multirow{2}{*}{ No } & \multirow{2}{*}{$\begin{array}{l}\text { Variasi Bahan } \\
\text { Tambah Semen } \\
\text { Limbah Karbit }\end{array}$} & \multicolumn{3}{|c|}{ Perbandingan Campuran } & \multirow{2}{*}{$\begin{array}{c}\text { Jumlah } \\
\text { Benda } \\
\text { Uji }\end{array}$} & \multirow{2}{*}{$\begin{array}{c}\text { Kode } \\
\text { Benda } \\
\text { Uji }\end{array}$} \\
\hline & & $\mathrm{Pc}$ & Pasir & Bottom ash & & \\
\hline 1 & $0 \%$ & 1 & 8 & & 3 & $\mathrm{~A} 01, \mathrm{~A} 02, \mathrm{~A} 03$ \\
\hline 2 & $10 \%$ & 1 & 8 & & 3 & $\mathrm{~A} 11, \mathrm{~A} 12, \mathrm{~A} 13$ \\
\hline 3 & $20 \%$ & 1 & 8 & & 3 & $\mathrm{~A} 21, \mathrm{~A} 22, \mathrm{~A} 23$ \\
\hline 4 & $30 \%$ & 1 & 8 & & 3 & $\mathrm{~A} 31, \mathrm{~A} 32, \mathrm{~A} 33$ \\
\hline 5 & $0 \%$ & 1 & & 8 & 3 & $\mathrm{~B} 01, \mathrm{~B} 02, \mathrm{~B} 03$ \\
\hline 6 & $10 \%$ & 1 & & 8 & 3 & $\mathrm{~B} 11, \mathrm{~B} 12, \mathrm{~B} 13$ \\
\hline 7 & $20 \%$ & 1 & & 8 & 3 & $\mathrm{~B} 21, \mathrm{~B} 22, \mathrm{~B} 33$ \\
\hline \multirow[t]{2}{*}{8} & $30 \%$ & 1 & & 8 & 3 & $\mathrm{~B} 31, \mathrm{~B} 32, \mathrm{~B} 33$ \\
\hline & \multicolumn{4}{|c|}{ Jumlah Benda Uji } & 24 & \\
\hline
\end{tabular}

Tabel 2. Hasil Pemeriksaan bottom ash

\begin{tabular}{ll}
\hline \multicolumn{1}{c}{$\begin{array}{c}\text { Jenis pemeriksaan pada } \\
\text { Bottom ash }\end{array}$} & Hasil Pengujian \\
\hline Bahan lewat saringan No. 200 & $8,7 \%$ \\
Analisa Saringan & $\mathrm{FM}=1,7$ \\
Berat Jenis & $1,25 \mathrm{gr} / \mathrm{cm}^{3}$ \\
Absorbsi & $2,8 \%$ \\
\hline
\end{tabular}

Tabel 3. Hasil Pemeriksaan Limbah karbit

\begin{tabular}{cc}
\hline $\begin{array}{c}\text { Jenis pemeriksaan pada } \\
\text { limbah karbit }\end{array}$ & Hasil Pengujian \\
\hline Berat Jenis & $2,27 \mathrm{gr} / \mathrm{cm}^{3}$ \\
Kehalusan & $2,50 \%$ \\
\hline
\end{tabular}

Tabel 4. Perencanaan campuran Batako

\begin{tabular}{cccc}
\hline $\begin{array}{c}\text { Kebutuhan } \\
\text { Pasir } \\
(\mathrm{kg})\end{array}$ & $\begin{array}{c}\text { Kebutuhan } \\
\text { bottom ash } \\
(\mathrm{kg})\end{array}$ & $\begin{array}{c}\text { Kebutuhan } \\
\text { Semen } \\
(\mathrm{kg})\end{array}$ & $\begin{array}{c}\text { Kebutuhan } \\
\text { Limbah Karbit } \\
(\mathrm{kg})\end{array}$ \\
\hline 10,99 & - & 1,73 & - \\
10,99 & - & 1,73 & 0,125 \\
10,99 & - & 1,73 & 0,250 \\
10,99 & - & 1,73 & 0,375 \\
- & 5,51 & 1,73 & - \\
- & 5,51 & 1,73 & 0,125 \\
- & 5,51 & 1,73 & 0,250 \\
- & 5,51 & 1,73 & 0,375 \\
\hline
\end{tabular}

Hasil Pengujian dan Perhitungan Batako Berat Jenis Batako
Hasil uji kuat tekan batako di dapat hasil sebagai berikut:

Tabel 5. Berat jenis batako

\begin{tabular}{ccccccccc}
\hline No & $\begin{array}{c}\text { Agregat } \\
\text { Halus }\end{array}$ & $\begin{array}{c}\text { Kode } \\
\text { Benda } \\
\text { Uji }\end{array}$ & $\begin{array}{c}\text { Variasi } \\
\text { LK } \\
(\%)\end{array}$ & $\begin{array}{c}(\mathrm{Bk}) \\
(\mathrm{Kg})\end{array}$ & $\begin{array}{c}(\mathrm{Ba}) \\
(\mathrm{Kg})\end{array}$ & $\begin{array}{c}\mathrm{Bk}-\mathrm{Ba} \\
(\mathrm{Kg})\end{array}$ & $\begin{array}{c}(\mathrm{Bj}) \\
(\mathrm{Kg})\end{array}$ & $\begin{array}{c}(\mathrm{Bj}) \text { rata } \\
- \text { rata } \\
(\mathrm{Kg})\end{array}$ \\
\hline 1 & & $\mathrm{~A} 01$ & $0 \%$ & 11.35 & 5.95 & 5.4 & 2.10 & \\
\hline
\end{tabular}




\begin{tabular}{|c|c|c|c|c|c|c|c|c|}
\hline 2 & & $\mathrm{~A} 02$ & $0 \%$ & 11.5 & 6.05 & 5.45 & 2.11 & 2.09 \\
\hline 3 & & $\mathrm{~A} 03$ & $0 \%$ & 11.05 & 5.7 & 5.35 & 2.07 & \\
\hline 4 & $\mathrm{P}$ & A11 & $10 \%$ & 11.1 & 5.7 & 5.4 & 2.06 & \\
\hline 5 & A & A 12 & $10 \%$ & 11.05 & 5.7 & 5.35 & 2.07 & 2.04 \\
\hline 6 & $\mathrm{~S}$ & A 13 & $10 \%$ & 10.85 & 5.45 & 5.4 & 2.01 & \\
\hline 7 & I & A 21 & $20 \%$ & 10.7 & 5.35 & 5.35 & 2.00 & \\
\hline 8 & $\mathrm{R}$ & A22 & $20 \%$ & 11.35 & 5.95 & 5.4 & 2.10 & 2.07 \\
\hline 9 & & A 23 & $20 \%$ & 11.55 & 6.1 & 5.45 & 2.12 & \\
\hline 10 & & A31 & $30 \%$ & 11.15 & 5.8 & 5.35 & 2.08 & \\
\hline 11 & & A 32 & $30 \%$ & 11.2 & 5.85 & 5.35 & 2.09 & 2.08 \\
\hline 12 & & A33 & $30 \%$ & 11.2 & 5.8 & 5.4 & 2.07 & \\
\hline 13 & & B01 & $0 \%$ & 5.75 & 1.15 & 4.6 & 1.25 & \\
\hline 14 & B & B02 & $0 \%$ & 5.8 & 1.2 & 4.6 & 1.26 & 1.25 \\
\hline 15 & $\mathrm{O}$ & B03 & $0 \%$ & 5.1 & 0.95 & 4.15 & 1.23 & \\
\hline 16 & $\mathrm{~T}$ & B11 & $10 \%$ & 6.7 & 1.75 & 4.95 & 1.35 & \\
\hline 17 & $\mathrm{~T}$ & B12 & $10 \%$ & 6.3 & 1.45 & 4.85 & 1.30 & 1.31 \\
\hline 18 & $\mathrm{O}$ & B13 & $10 \%$ & 6.15 & 1.3 & 4.85 & 1.27 & \\
\hline 19 & M & B21 & $20 \%$ & 6.95 & 1.8 & 5.15 & 1.35 & \\
\hline 20 & & B22 & $20 \%$ & 7.65 & 2.45 & 5.2 & 1.47 & 1.38 \\
\hline 21 & A & B23 & $20 \%$ & 6.65 & 1.6 & 5.05 & 1.32 & \\
\hline 22 & $\mathrm{~S}$ & B31 & $30 \%$ & 7.3 & 2.05 & 5.25 & 1.39 & \\
\hline 23 & $\mathrm{H}$ & B32 & $30 \%$ & 6.25 & 1.35 & 4.9 & 1.28 & 1.33 \\
\hline 24 & & B33 & $30 \%$ & 6.7 & 1.6 & 5.1 & 1.31 & \\
\hline
\end{tabular}

Sumber : Hasil Penelitian

Rumus Berat jenis :

$$
\mathrm{Bj}=\frac{B k}{(B k-B a)}
$$

Dari hasil perhitungan didapatkan grafik sebagai berikut :

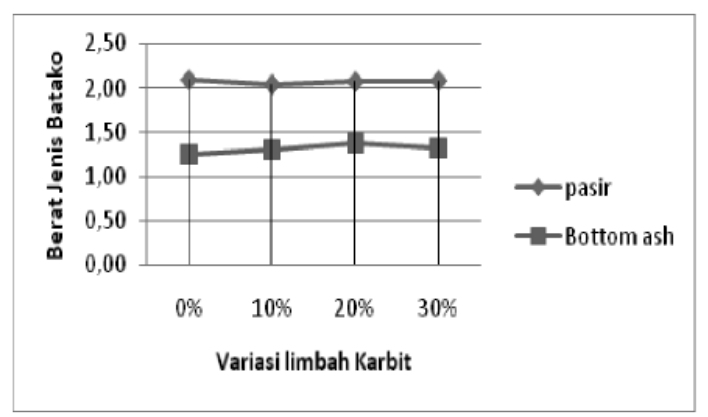

Gambar 1. Grafik hubungan antara berat jenis batako dengan variasi limbah karbit
Dari hasil pengujian berat jenis dapat di ketahui batako dengan menggunakan pasir sebagai agregat halusnya memiliki berat jenis $2,04 \mathrm{~kg} / \mathrm{cm}^{3}$ bottom ash pada variasi limbah karbit $10 \%$ sedangkan batako yang menggunakan sebagai agregat halunya memiliki berat jenis yang lebih ringan $1,25 \mathrm{~kg} / \mathrm{cm}^{3}$ pada variasi limbah karbit $0 \%$. Pada pengujian ini pengaruh penambahan variasi limbah karbit terlihat tidak terlalu besar terhadap berat jenis batako.

\section{Kuat Tekan Batako}

Hasil uji kuat tekan batako di dapat hasil sebagai berikut:

Tabel 6. Uji kuat tekan batako

\begin{tabular}{|c|c|c|c|c|c|c|c|c|}
\hline No & $\begin{array}{l}\text { Agregat } \\
\text { Halus }\end{array}$ & $\begin{array}{c}\text { Kode } \\
\text { Benda } \\
\text { Uji }\end{array}$ & $\begin{array}{c}\text { Variasi } \\
\text { Penggantian } \\
\text { LK }(\%)\end{array}$ & $\begin{array}{l}\text { Beban } \\
\text { Max } \\
(\mathrm{KN})\end{array}$ & $\begin{array}{l}\text { Beban } \\
\text { Max } \\
(\mathrm{N})\end{array}$ & $\begin{array}{c}\mathrm{A} \\
\left(\mathrm{mm}^{2}\right)\end{array}$ & $\begin{array}{c}\text { KuatTekan } \\
* \\
\left(\mathrm{~N} / \mathrm{mm}^{2}\right)\end{array}$ & $\begin{array}{c}\text { Kuat Tekan } \\
\text { Ratarata } \\
\left(\mathrm{N} / \mathrm{mm}^{2}\right)\end{array}$ \\
\hline 1 & & A01 & $0 \%$ & 136.364 & 136363.64 & 26037.5 & 5.24 & \\
\hline 2 & & A02 & $0 \%$ & 113.636 & 113636.36 & 26037.5 & 4.36 & 4.87 \\
\hline 3 & & A03 & $0 \%$ & 130.682 & 130681.82 & 26037.5 & 5.02 & \\
\hline
\end{tabular}




\begin{tabular}{lllllllll}
\hline 4 & P & A11 & $10 \%$ & 142.045 & 142045.45 & 26037.5 & 5.46 & \\
5 & A & A12 & $10 \%$ & 142.045 & 142045.45 & 26037.5 & 5.46 & 5.31 \\
6 & S & A13 & $10 \%$ & 130.682 & 130681.82 & 26037.5 & 5.02 & \\
7 & I & A21 & $20 \%$ & 159.091 & 159090.91 & 26037.5 & 6.11 & \\
8 & R & A22 & $20 \%$ & 136.364 & 136363.64 & 26037.5 & 5.24 & 5.82 \\
9 & & A23 & $20 \%$ & 159.091 & 159090.91 & 26037.5 & 6.11 & \\
10 & & A31 & $30 \%$ & 181.818 & 181818.18 & 26037.5 & 6.98 & \\
11 & & A32 & $30 \%$ & 176.136 & 176136.36 & 26037.5 & 6.76 & 6.91 \\
12 & & A33 & $30 \%$ & 181.818 & 181818.18 & 26037.5 & 6.98 & \\
13 & & B01 & $0 \%$ & 56.818 & 56818.182 & 26037.5 & 2.18 & \\
\hline 14 & B & B02 & $0 \%$ & 45.455 & 45454.545 & 26037.5 & 1.75 & 1.96 \\
15 & O & B03 & $0 \%$ & 51.136 & 51136.364 & 26037.5 & 1.96 & \\
16 & T & B11 & $10 \%$ & 102.273 & 102272.73 & 26037.5 & 3.93 & \\
17 & T & B12 & $10 \%$ & 79.545 & 79545.455 & 26037.5 & 3.06 & 3.49 \\
18 & O & B13 & $10 \%$ & 90.909 & 90909.091 & 26037.5 & 3.49 & \\
19 & M & B21 & $20 \%$ & 130.682 & 130681.82 & 26037.5 & 5.02 & \\
20 & & B22 & $20 \%$ & 125.000 & 125000 & 26037.5 & 4.80 & 4.80 \\
21 & A & B23 & $20 \%$ & 119.318 & 119318.18 & 26037.5 & 4.58 & \\
22 & S & B31 & $30 \%$ & 142.045 & 142045.45 & 26037.5 & 5.46 & \\
23 & H & B32 & $30 \%$ & 130.682 & 130681.82 & 26037.5 & 5.02 & 5.24 \\
24 & & B33 & $30 \%$ & 136.364 & 136363.64 & 26037.5 & 5.24 & \\
\hline
\end{tabular}

Sumber : Hasil Penelitian

* Rumus Kuat Tekan : $\quad f^{\prime} \mathrm{c}=\frac{F}{A}$

Dari hasil perhitungan didapatkan grafik sebagai berikut :

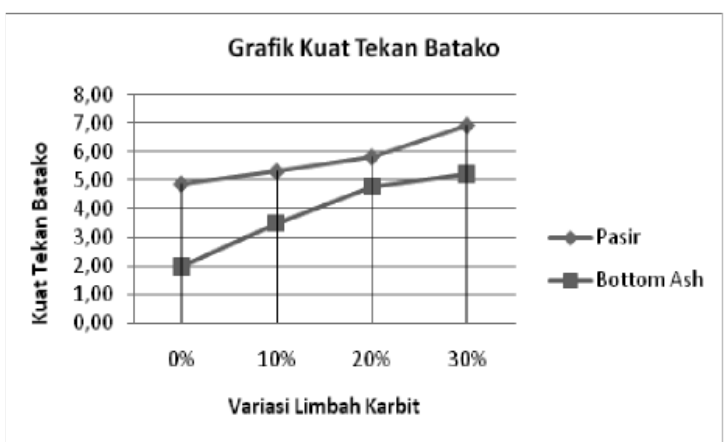

Gambar 2. Grafik hubungan antara kuat tekan batako dengan variasi limbah karbit
Dari hasil pengujian kuat tekan yang dilakukan dapat disimpulkan dengan semakin besarnya persentase agregat limbah karbit pada campuran batako maka kuat tekannya semakin bertambah. Kuat tekan tertinggi terjadi pada variasi $30 \%$ yaitu sebesar 69,10 MPa batako dengan menggunakan pasir sebagai agregat halus sedangkan batako yang menggunakan bottom ash kuat tekan terbaik tejadi pada variasi limbah karbit 30\% yaitu sebesar 52,37 MPa.

\section{Absorbsi Batako}

Hasil absorbsi batako didapat seperti berikut:

Tabel 7. Uji absorbsi batako

\begin{tabular}{|c|c|c|c|c|c|c|c|}
\hline No & $\begin{array}{l}\text { Agregat } \\
\text { Halus }\end{array}$ & $\begin{array}{c}\text { Kode } \\
\text { Benda } \\
\text { Uji }\end{array}$ & $\begin{array}{c}\text { Persentase } \\
\text { Variasi } \\
\text { Limbah } \\
\text { Karbit }\end{array}$ & $\begin{array}{c}\text { Berat } \\
\text { Kering } \\
\text { Permukaan } \\
(\mathrm{kg})\end{array}$ & $\begin{array}{l}\text { Berat } \\
\text { Kering } \\
\text { Oven } \\
(\mathrm{kg})\end{array}$ & Absorbsi & $\begin{array}{c}\text { Absorbsi } \\
\text { rata-rata } \\
\\
(\%)\end{array}$ \\
\hline 1 & & A01 & $0 \%$ & 11.85 & 11.35 & 4.41 & \\
\hline 2 & & A02 & $0 \%$ & 11.9 & 11.5 & 3.48 & 5.49 \\
\hline 3 & & A03 & $0 \%$ & 12 & 11.05 & 8.60 & \\
\hline 4 & $P$ & A11 & $10 \%$ & 11.7 & 11.1 & 5.41 & \\
\hline 5 & A & $\mathrm{A} 12$ & $10 \%$ & 11.5 & 11.05 & 4.07 & 4.54 \\
\hline 6 & $\mathrm{~S}$ & A13 & $10 \%$ & 11.3 & 10.85 & 4.15 & \\
\hline 7 & I & A21 & $20 \%$ & 11.35 & 10.7 & 6.07 & \\
\hline 8 & $\mathrm{R}$ & A22 & $20 \%$ & 11.65 & 11.35 & 2.64 & 3.92 \\
\hline 9 & & A23 & $20 \%$ & 11.9 & 11.55 & 3.03 & \\
\hline 10 & & A31 & $30 \%$ & 11.65 & 11.15 & 4.48 & \\
\hline 11 & & A32 & $30 \%$ & 11.7 & 11.2 & 4.46 & 3.58 \\
\hline 12 & & A33 & $30 \%$ & 11.4 & 11.2 & 1.79 & \\
\hline 13 & & B01 & $0 \%$ & 6.65 & 5.75 & 15.65 & \\
\hline
\end{tabular}




\begin{tabular}{lllccccc}
\hline 14 & B & B02 & $0 \%$ & 6.3 & 5.8 & 8.62 & 12.01 \\
15 & O & B03 & $0 \%$ & 5.7 & 5.1 & 11.76 & \\
16 & T & B11 & $10 \%$ & 7.3 & 6.7 & 8.96 & \\
17 & T & B12 & $10 \%$ & 6.8 & 6.3 & 7.94 & 10.78 \\
18 & O & B13 & $10 \%$ & 7.1 & 6.15 & 15.45 & \\
19 & M & B21 & $20 \%$ & 7.45 & 6.95 & 7.19 & \\
20 & & B22 & $20 \%$ & 8.25 & 7.65 & 7.84 & 7.52 \\
21 & A & B23 & $20 \%$ & 7.15 & 6.65 & 7.52 & \\
22 & S & B31 & $30 \%$ & 7.8 & 7.3 & 6.85 & \\
23 & H & B32 & $30 \%$ & 6.7 & 6.25 & 7.20 & 6.92 \\
24 & & B33 & $30 \%$ & 7.15 & 6.7 & 6.72 & \\
\hline
\end{tabular}

Sumber : Hasil Penelitian

Rumus absorbsi : \% absorbsi $=\left(\frac{B-A}{A}\right) \times 100 \%$

Dari hasil perhitungan didapatkan grafik sebagai berikut :

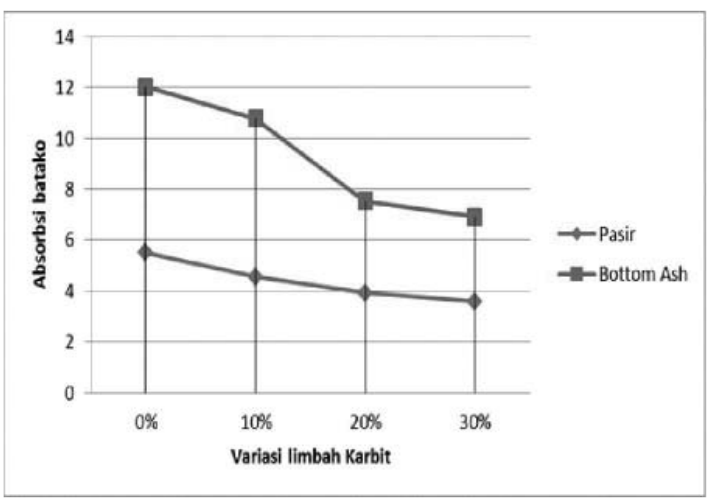

Gambar 3. Grafik hubungan antara absorbsi batako dengan variasi limbah karbit

\section{KESIMPULAN DAN SARAN}

\section{Kesimpulan}

Dari hasil penelitian yang telah dilakukan dapat diambil kesimpulan sebagai berikut :

- $\quad$ Berat jenis batako dengan menggunakan pasir sebagai agregat halusnya memiliki berat jenis 2.9 kg pada variasi limbah karbit $0 \%$ sedangkan batako yang menggunakan bottom ash sebagai agregat halunya memiliki berat jenis yang lebih ringan $1.25 \mathrm{~kg}$ pada variasi limbah karbit $0 \%$.

- Batako normal dengan agregat halusnya menggunakan pasir memiliki kuat tekan 4.87 MPa kemudian diberikan variasi limbah karbit sebagai bahan tambah semen sebesar 10\%, $20 \%$, dan 30\% maka didapat kuat tekan maksimal pada variasi 30\% dengan kuat tekan 6.91 MPa. Kemudian agregat halus di ganti dengan bottom ash dengan variasi limbah karbit $0 \%$ didapat kuat tekan $1.96 \mathrm{MPa}$, diberikan variasi limbah karbit 10\%, 20\%, dan $30 \%$ maka di dapat kuat tekan maksimal pada variasi limbah karbit 30\% sebesar 5.23 $\mathrm{MPa}$.

- Batako normal dengan agregat halusnya menggunakan pasir memiliki absorbsi 5,49\% kemudian diberikan variasi limbah karbit sebagai bahan tambah semen sebesar 10\%, 20\%, dan $30 \%$ maka didapat absorbsi lebih kecil pada variasi $30 \%$ yaitu 3,58\%. Kemudian agregat halus di ganti dengan bottom ash dengan variasi limbah karbit $0 \%$ didapat absorbsi $12,01 \%$, diberikan variasi limbah karbit 10\%, $20 \%$, dan $30 \%$ maka di dapat absorbsi lebih kecil pada variasi limbah karbit 30\% sebesar $6,92 \%$.

\section{Saran}

Untuk rekomendasi bagi penelitian selanjutnya, diberikan saran-saran sebagai berikut :

- Disarankan untuk mengadakan penelitian kembali dengan variasi ukuran butir pada agregat limbah batu bara bottom ash, untuk mengetahui ukuran butir yang dapat menghasilkan kekuatan batako yang optimum.

- Disarankan untuk mengadakan penelitian kembali dengan melakukan penggantian agregat halus pasir dengal limbah batu bara (bottom ash) untuk menghasilkan kekuatan batako yang optimum.

- Disarankan untuk mengadakan penelitian kembali dengan melakukan penambahan persentase variasi limbah karbit sehingga dapat menghasilkan kekuatan batako yang optimum.

- Dalam penelitian pada waktu pelaksanaan pembuatan batako, material dan alat-alat yang digunakan harus diupayakan dalam keadaan 
SSD karena untuk mengatasi jumlah faktor air semen (FAS) yang benar-benar dibutuhkan oleh agregat.

\section{DAFTAR PUSTAKA}

Anonim, 2010, "Buku petunjuk praktikum Teknologi Beton", Universitas Muhammadiyah Malang

Asrori Mokh Rozaq, "Pengaruh Penambahan Limbah Karbit Pt. Samator Gas Industri Terhadap Besarnya Kuat Tekan Bebas (Qu) Pada Tanah Lempung Ekspansif'. Surabaya, Universitas Negri Surabaya: Tidak diterbitkan Harvey, Ghafoori,1998,Coal Bottom Ash/Boiler Slag-Asphalt Concrete, Jakarta

Hendratmo Muji Utomo, 2010, "Analisis Kuat Tekan Batako Dengan Limbah Karbit Sebagai Bahan Tambah". Yogyakarta, Universitas Negri Yogyakarta: Tidak diterbitkan

Hermanus Patrick Adolf Yohanes, Lapu Andrias Sanda, 2001, "Perilaku Penggunaan Bottom Ash Pada Campuran Aspal Beton", Surabaya, Universitas Kristen Petra : Tidak diterbitkan

Mulyono, T, 2003, “Teknologi Beton”, Universitas Negeri Jakarta. Jakarta. 2003

Suhilman Alex Budiarto, Santoso Christiano Budi, 2007, "Pengaruh Limbah Karbit dan Fly Ash Terhadap Kekuatan Mortar", Surabaya, Universitas Keristen Petra: Tidak diterbitkan

Tjokrodimuljo Kardiyono, 1992, "Kekuatan Pasta Semen dan Faktor Air Semen", Yogyakarta Universitas Gajah Mada

Tjokrodimuljo Kardiyono, 1996, “Teknologi Beton”, Yogyakarta, Naviri 